ISSN: 2277-3754

ISO 9001:2008 Certified

International Journal of Engineering and Innovative Technology (IJEIT)

Volume 10, Issue 6, December 2020

\title{
Comparison of Cumulative Equivalent Standard Axle Load of heavy vehicles under various load conditions
}

\author{
Aji Suraji, Agus Tugas Sujianto, Riman
}

Department of Civil Engineering, University Widyagama, Malang

Abstract: Heavy vehicles in highway traffic, especially primary arterial national roads, have different loading conditions, namely heavy, medium, or empty loads. The assumption of the vehicle's load will have consequences for the value of the Cumulative Standard Axle Load or referred to as CESA (Cumulative Equivalent Standard Axle Load). This paper aims to analyze the difference in the value of CESA of heavy vehicles under charged conditions and in an empty condition. The method used in this analysis is to conduct a traffic count survey on the Caruban-Ngawi road segment by distinguishing the condition of the charged vehicle and being empty. Then each vehicle type is calculated by Vehicle Damage Factor (VDF). With the assumption that the traffic growth value is $5 \%$ and the design life is 10 years, the CESA value can be determined. The results of the traffic count survey on the road section found that the proportion of heavy vehicles passing in conditions not carrying cargo or in an empty condition in the range of $35.71 \%$ of the total commercial vehicles. The results of the analysis show that there is a significant difference in the CESA value between the conditions of the vehicle containing the charge with the assumption that there is a medium vehicle not containing the load. The difference between the conditions of the vehicle contains a charge with the assumption that there is a vehicle not containing a load of $39.02 \%$ lower.

Keywords: Road, Heavy vehicle, Load, Axle load, CESA.

\section{BACKGROUND}

Heavy vehicles passing on a road have various load conditions. In general, the condition of heavy vehicle loads is distinguished from those containing cargo and not containing cargo. The load condition is very logical because basically a heavy vehicle has an assignment to send goods to a place after that back to the base again in an empty state. The two conditions of the load will have implications for the assumption that the real axis load is different. In general, the characteristics of traffic on road links in accordance with the Regulation of the Minister of Public Works No. 03/PRT/M/2012, concerning Guidelines for Determining Road Functions and Road Status.

Meanwhile based on the Pavement Design Manual (MDP) both in the 2013 MDP and 2017 MDP, heavy loaded vehicles also have a variety of load conditions, ranging from light, medium, or heavy load contents. With these various types of load, the value of Axis Load Equivalence or Vehicle Damage Factor is also different.

\footnotetext{
Manuscript received: 18 November 2020

Manuscript received in revised form: 14 December 2020

Manuscript accepted: 31 December 2020

Manuscript Available online: 15 January 2021
}

of the existence of heavy vehicles in an empty cargo condition. This is also in accordance with the Regulation of the Minister of Public Works No. 19/PRT/M/2011, concerning Road Technical Requirements and Road Technical Planning Criteria and Regulation of the Minister of Public Works No. 03/PRT/M/2012, concerning Guidelines for Determining Road Functions and Road Status.

The road pavement planning method of PTT 2002 still has not fully adopted the existence of more burden for heavy vehicles. Whereas the MDP 2013 method and MDP 2017 have adopted the assumption that there are heavy vehicles that are overloaded. Adopting more loads on heavy vehicles is very important in an effort to get maximum results nearing the reality in the field. This argument is very relevant because the reality in heavy vehicle fields is more likely to occur overload. This is in accordance with the results of research conducted by [4], [7]. By looking at the existence of heavy vehicles in the condition of no load (blank) as analyzed in this paper, it will further sharpen the intent of the effort to approach the reality of the field.

As the research that has been conducted by Suraji et al [10] that the proportion of heavy vehicles on national roads in percentage is not too high but the contribution to the CESA value is very large. This is due to the VDF value of heavy vehicles that have more loads having a very high VDF value. Broadly speaking, it can be said that the problem of heavy vehicles has two main things, namely the high VDF contribution, and on the other hand the unloaded heavy vehicles have low VDF values. Thus the assumption of the existence of heavy vehicles in road pavement design must be more accurate because they have different impacts on CESA values. The purpose of this study is to determine the proportion of heavy vehicles to total commercial vehicles and to know the difference in CESA values between heavy vehicles based on the MDP 2017 method and the CESA value with the assumption of a vehicle that is not charged.

\section{RESEARCH METHOD}

The design of the research activity begins with a traffic default survey and the determination of Average Daily Traffic (ADT), followed by CESA calculation for heavy vehicles based on MDP 2017 and the assumption of heavy vehicles that are not charged. The location as the object of research is the Caruban-Ngawi road with a length of about $40 \mathrm{~km}$, where this road is the primary 
ISSN: 2277-3754

ISO 9001:2008 Certified

\section{International Journal of Engineering and Innovative Technology (IJEIT)}

Volume 10, Issue 6, December 2020

arterial road status of the national road that connects the Surabaya-Yogyakarta corridor. Picture of the location of the Caruban-Ngawi road as shown in Figure 1.

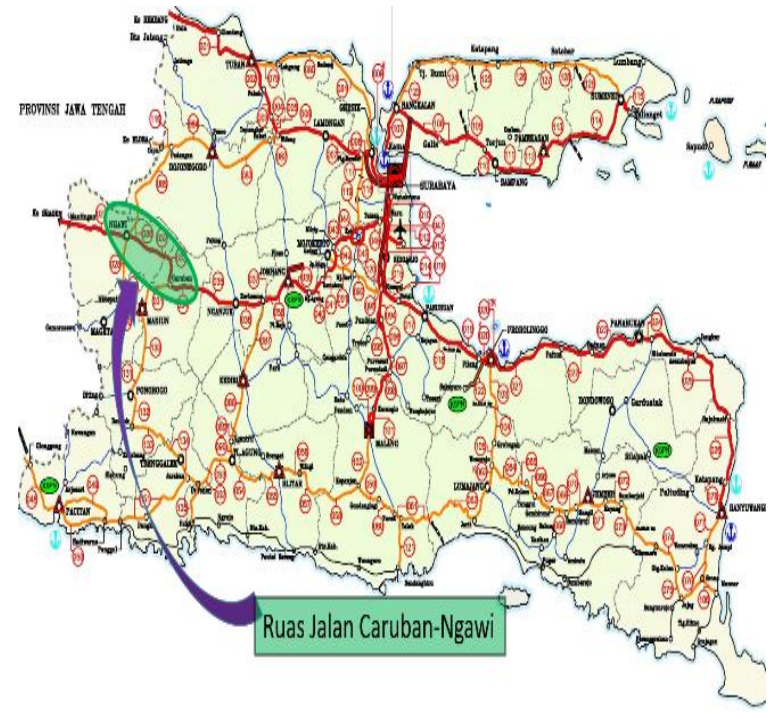

Fig 1: Research location of Caruban Ngawi Road Segment

Traffic counts are surveyed 24 hours a day by sorting out vehicle classes based on the MDP 2017 method by adding information to heavy vehicles that are not charged. Identification of heavy vehicles that are not charged is done by seeing visually the condition of the truck body in a filled or unfilled condition. If visually the load cannot be identified, then another method is done by looking at the vehicle movement behavior. If a heavy vehicle can go fast then it can be assumed that the heavy vehicle is in a non-charged condition. Illustration of types of heavy or uncharged vehicles as shown in Figure 2.

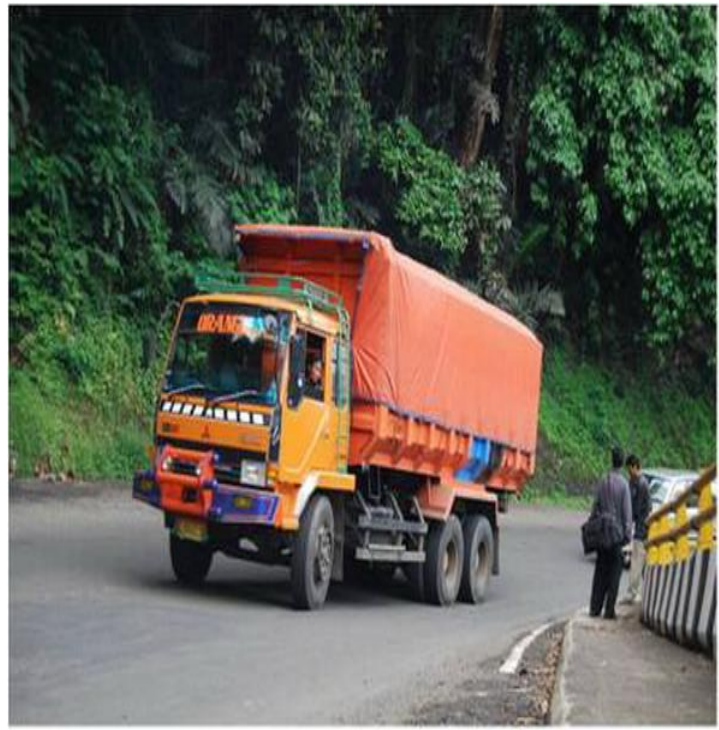

Fig 2: Sample of heavy vehicle with overload condition

Data analysis techniques are carried out by determining the proportion of heavy vehicle types to the total number of commercial vehicles. Furthermore, unloaded heavy vehicles are sorted separately and the VDF is calculated. The calculation of VDF for empty vehicles is based on the formula contained in the PTT 2002 method. Calculation of CESA for the two conditions of heavy vehicles in accordance with the MDP 2017 method and unloaded heavy vehicles can be determined.

\section{RESULT AND DICUSSION}

The results of the traffic survey on the Caruban-Ngawi road for 24 hours have resulted in the LHR as shown in Table 1 column 3 . In the table is the entire vehicle that passes on the road, including motorbikes, light vehicles, or heavy vehicles or also called commercial vehicle. Specifically for heavy vehicles at the time of survey, separate heavy vehicles that do not carry cargo. Data of heavy vehicles that do not carry cargo as shown in Table 2 column 3. From these data can be calculated the percentage of heavy vehicles that do not carry cargo that is equal to $35.71 \%$ of the total commercial vehicles. Types of commercial vehicles can be seen in Table 1 column 1 , which includes commercial vehicles ranging from groups 5 to class 7 . Judging from the percentage of heavy vehicles without load, it can be said that the difference in percentage of $35.71 \%$ is very large.

Traffic projections for planning predictions are assumed to be 10 years of plan and $5 \%$ of traffic growth. Furthermore, CESA is calculated based on LHR, ESA, VDF data and traffic multiplier factors. The calculation of CESA is divided into two conditions, based on the composition of traffic according to the MDP 2017 method which does not distinguish between heavy and unloaded vehicles. While the other CESA calculation is to assume the condition of heavy and unloaded vehicles.

The results of the CESA calculation for the two assumptions are as shown in Table 1 and Table 2 for each of them in the condition of heavy vehicles based on 2017 MDP and heavy unloaded vehicles. From the calculation, the CESA value based on the MDP 2017 method is 419.8 . While the CESA calculation makes the assumption that there is a heavy vehicle without a load, it is obtained as 256.0. Based on the results of the calculation of the two CESA, the CESA value can be calculated on the condition of heavy vehicles without carrying a charge which has a lower value of 163.8 or $39.01 \%$.

The difference between the CESA values and the different conditions can be said that the values differ very significantly. Of course the significant difference in CESA values will have implications for the thickness of the road pavement structure and the construction costs required.

The results of this study certainly strengthens the results of previous studies that discuss traffic for heavy vehicles as has been done by [4] [7] More specifically, Suraji et al [10] have also conducted research related to this topic where the proportion of heavy vehicles although the percentage of overall traffic that passes on the road is not large but the contribution of damage caused is relatively greater. 
ISSN: 2277-3754

ISO 9001:2008 Certified

International Journal of Engineering and Innovative Technology (IJEIT)

Volume 10, Issue 6, December 2020

Table 1: CESA Calculation on Caruban-Ngawi Road based on MDP 2017

\begin{tabular}{|c|c|c|c|c|c|}
\hline Category & Vehicles & $\begin{array}{c}\text { ADT } \\
\text { (Veh/day) }\end{array}$ & VDF $^{\mathbf{5}}$ & ESA & $\operatorname{CESA}^{5}$ \\
\hline 1 & Motor cycle & 3905 & $\mathbf{0}$ & 0 & 0 \\
\hline 2 & Car & 2335 & $\mathbf{0}$ & 0 & 0 \\
\hline 3 & Paratransit & 442 & $\mathbf{0}$ & 0 & 0 \\
\hline 4 & Pick up & 471 & 0 & 0 & 0 \\
\hline $5 a$ & Mini Bus (1.2) & 153 & 0.2 & 30.6 & 140482 \\
\hline $5 b$ & Bus (1.2) & 150 & 1 & 150 & 688640 \\
\hline $6 a 1$ & Truck 2 axle light cargo (1.1) & 309 & 0.2 & 61.8 & 283720 \\
\hline $6 a 2$ & Truck 2 axle, light (1.2) & 645 & 0.8 & 516 & 2368920 \\
\hline $6 b 1.1$ & Truck 2 axle, medium cargo & 357 & 0.7 & 249.9 & 1147274 \\
\hline $6 \mathrm{~b} 1.2$ & Truck 2 axle, medium & 208 & 1.7 & 353.6 & 1623353 \\
\hline $6 \mathrm{~b} 2.1$ & Truck 2 axle, heavy (public cargo) & 153 & 0.8 & 122.4 & 561930 \\
\hline $6 b 2.1$ & Truck 2 axle, heavy (soil, cement) & 162 & 11.2 & 1814.4 & 8329785 \\
\hline $7 a 1$ & Truck 3 axle, light & 257 & 11.2 & 2878.4 & 13214535 \\
\hline $7 a 3$ & Truck 3 axles, heavy & 141 & 62.2 & 8770.2 & 40263381 \\
\hline $7 \mathrm{~b}$ & Truck 2 axles and trailler 2 axles (1.2-2.2) & 214 & 90.4 & 19345.6 & 88814310 \\
\hline $7 \mathrm{c1}$ & Truck 4 axles - trailer $(1.2-22)$ & 230 & 24 & 5520 & 25341938 \\
\hline $7 c 2.1$ & Truck 5 axles - trailer $(1.22-22)$ & 232 & 33.2 & 7702.4 & 35361185 \\
\hline $7 \mathrm{c} 2.2$ & Truck 5 axles - trailer (1.2-222) & 224 & 69.7 & 15612.8 & 71677284 \\
\hline \multirow[t]{3}{*}{$7 \mathrm{c} 3$} & Truck 6 axles - trailer (1.22-222) & 208 & 93.7 & 19489.6 & 89475404 \\
\hline & & & & Total & 419797006 \\
\hline & & & & & $419.8 \times 10^{6}$ \\
\hline
\end{tabular}

Table 2: CESA Calculation on Caruban-Ngawi Road without charge

\begin{tabular}{|c|c|c|c|c|c|c|}
\hline Category & $\begin{array}{c}\text { Gategory based } \\
\text { MDP } 2017\end{array}$ & Vehicles & $\begin{array}{c}\text { ADT } \\
\text { (Veh/day) }\end{array}$ & VDF $^{5}$ & ESA & CESA $^{5}$ \\
\hline 1 & 1 & Motor cycle & 3905 & 0.0000 & 0.0 & 0 \\
\hline 2 & 2 & Car & 2335 & 0.0000 & 0.0 & 0 \\
\hline 3 & 3 & Paratransit & 442 & 0.0000 & 0.0 & 0 \\
\hline 4 & 4 & Pick Up & 471 & 0.0000 & 0.0 & 0 \\
\hline $5 a$ & $5 a$ & Mini Bus & 153 & 0.2000 & 30.6 & 140482 \\
\hline $5 b$ & $5 b$ & Bus & 150 & 1.0000 & 150.0 & 688640 \\
\hline \multirow{2}{*}{$6 a .1$} & \multirow{2}{*}{$6 a 1$} & Truck 2 axles, light cargo (empty) & 154 & 0.0001 & 0.0 & 45 \\
\hline & & Truck 2 axles, light cargo (charged) & 155 & 0.2000 & 31.0 & 142319 \\
\hline \multirow{2}{*}{$6 a .2$} & \multirow{2}{*}{$6 . \mathrm{a} 2$} & Truck 2 axles light (empty) & 207 & 0.0006 & 0.1 & 540 \\
\hline & & Truck 2 axles light (charged) & 438 & 0.8000 & 350.4 & 1608662 \\
\hline 6b.1 & & Truck 2 axles cargo (empty) & 170 & 0.0008 & 0.1 & 619 \\
\hline $6 \mathrm{~b} 1.1$ & & \begin{tabular}{|l|} 
Truck 2 axles cargo (charged) \\
\end{tabular} & 187 & 0.7000 & 130.9 & 600953 \\
\hline $6 \mathrm{~b} 1.2$ & $6 \mathrm{~b}$ & Truck 2 axles cargo (medium) & 208 & 1.7000 & 353.6 & 1623353 \\
\hline $6 \mathrm{~b} .2$ & OD & Truck 2 axles, heavy (empty) & 202 & 0.0052 & 1.1 & 4822 \\
\hline 6b.2.2 & & Truck 2 axles, heavy (overload) & 162 & 11.2000 & 1814.4 & 8329785 \\
\hline $7 \mathrm{a}$ & & Truck 3 axles (empty) & 123 & 0.0270 & 3.3 & 15260 \\
\hline $7 \mathrm{a} 1$ & 79 & Truck 3 axles (light) & 134 & 11.2000 & 1500.8 & 6890069 \\
\hline $7 \mathrm{a} 2$ & /d & Truck 3 axles (mendium) & 137 & 64.4000 & 8822.8 & 40504864 \\
\hline $7 a 3$ & & Truck 3 axles (overload) & 141 & 62.2000 & 8770.2 & 40263381 \\
\hline & $7 \mathrm{~b}$ & Truck 2 axles and trailler 2 axles (1.2-2.2) & 102 & 0.0030 & 0.3 & 1400 \\
\hline & ס & Truck 2 axles and trailler 2 axles $(1.2-2.2)$ & 112 & 90.4000 & 10124.8 & 46482256 \\
\hline 7 & & Truck 4 axles - trailer (1.2-22) (empty) & 124 & 0.0145 & 1.8 & 8260 \\
\hline /c1 & & Truck 4 axles - trailer (1.2-22) (overload) & 106 & 24.0000 & 2544.0 & 11679328 \\
\hline $7 c 21$ & & Truck 5 axles - trailer (1.22-22) (empty) & 121 & 0.0169 & 2.0 & 9377 \\
\hline$/ \mathrm{c} 2.1$ & $7 r$ & Truck 5 axles - trailer (1.22-22) (overload) & 111 & 33.2000 & 3685.2 & 16918498 \\
\hline $7 \times 23$ & re & Truck 5 axles - trailer (1.2-222) (empty) & 113 & 0.1353 & 15.3 & 70178 \\
\hline $7 c 2.2$ & & Truck 5 axles - trailer (1.2-222) (overload) & 111 & 69.7000 & 7736.7 & 35518654 \\
\hline 73 & & Truck 6 axles - trailer (1.22-222) (empty) & 106 & 0.0306 & 3.2 & 14878 \\
\hline (1) & & Truck 6 axles - trailer $(1.22-222)$ (overloa & 102 & 93.7000 & 9557.4 & 43877362 \\
\hline
\end{tabular}


ISSN: 2277-3754

ISO 9001:2008 Certified

International Journal of Engineering and Innovative Technology (IJEIT)

Volume 10, Issue 6, December 2020

\section{CONCLUSION}

From the results of the analysis of the CESA value of heavy vehicles it can be concluded that:

1) The proportion of heavy vehicles without payload is $35.71 \%$ of total vehicles, where the proportion is in the large category.

2) There is a significant difference in CESA values between heavy vehicles that are loaded based on the MDP 2017 method and non-load heavy vehicles, which is $39.01 \%$. This will have implications for the results of the thick design of the pavement structure.

\section{REFERENCES}

[1] Directorate General of Highways, Road Pavement Design Manual, No. 02 / M / BM / 2013, Ministry of Public Works, 2013.

[2] Directorate General of Highways. Directorate General of Highways, Road Pavement Design Manual, No. 02 / M / BM / 2017, Ministry of Public Works, 2017.

[3] Directorate General of Highways. Department of Settlement and Regional Infrastructure, Guidelines for Planning Flexible Pavement Thickness, Pt T-01-2002-B, 2002.

[4] Idham, M, "Impact Analysis and Handling of Heavy Vehicle Overload in Riau Province (An Overview of the Economic Perspective Aspects)", Invotek Journal, Vol. 2, No. 1. Department of Civil Engineering, Bengkalis State Polytechnic, pp. 87-95, 2012.

[5] Minister of Public Works Regulation No. 19 / PRT / M / 2011, concerning Road Technical Requirements and Road Technical Planning Criteria, Minister of Public Works of the Republic of Indonesia, 2011.

[6] Minister of Public Works Regulation No. 03 / PRT / M / 2012, concerning Guidelines for Determination of Road Functions and Road Status, Minister of Public Works of the Republic of Indonesia, 2012.

[7] Sentosa, L. and Roza, A.A, "Impact Analysis of Vehicle Overloading on Rigid Pavement Structures on Pavement Planning Age (Case Study of Simp Lago - Sorek Road Section Km 77 to 78)", Journal of Civil Engineering, Vol. 19 No. 2, University of Riau, pp. 161-167, 2012.

[8] Suraji A, Sudjianto AT,"Review of Road Pavement Structure Design by Considering the Overload Effect", 2016 Indonesian Lecturer Forum National Seminar (FDI), University of Widyagama Malang, pp. TS18-TS23, 2016.

[9] Suraji A, Sudjianto AT, Riman, Aditya C., "The Effect of Overload of Heavy Vehicles on Load Equivalent Factors (VDF) on the Caruban-Ngawi Road Section”, 2016 National Civil Engineering Seminar II, Narotama University. Surabaya, pp. 104-113, 2016.

[10] Suraji A, Sudjianto AT, Riman, Aditya C. ,"Characteristics of Traffic Flow on the Caruban-Ngawi Road Section and the Proportion of Heavy Vehicles During 24 Hours of Observation", National Seminar on the Application of Regional Infrastructure Technology (ATPW), pp:1-4, 2017. 